\title{
Afterward: Making Meaning After a Frightening Near-Death Experience
}

\author{
Nancy Evans Bush, M.A. \\ Bolton, $C T$
}

$A B S T R A C T$ : The routes by which individuals attribute meaning to a neardeath experience (NDE) appear to be similar, whether the experience was radiant or terrifying. This article explores three such avenues in relation to frightening experiences. I argue that resisting a terrifying NDE is likely to intensify fearfulness in an individual, and also that a similar effect occurs within society when this type of experience is resisted and misunderstood. The article concludes with an approach to synthesis and suggested techniques that may be useful in integrating the experience.

KEY WORDS: frightening near-death experience; hellish near-death experience; hero's journey archetype; meaning of near-death experience; integrating near-death experience.

Easy is the descent to Hades:

Night and day the door stands open;

But to recall the steps and pass out to the upper air,

This is the task, this the toil!

Virgil, Aeneid, Book VI.126

As far back in human history as we can see, however dimly, we find stories of light-filled ecstasies and of descent into frightening landscapes. Often associated with death and afterlife, and perhaps equally with the quest for hidden treasure, the stories come from around the globe-from Sumer, Mesopotamia, Greece, Egypt, the countries of Asia and Europe, and the pre-Columbian Americas. The names of their Underworld travelers include Inanna, Tammuz, Ishtar, Gilgamesh, Enoch, Orpheus, Hercules, Persephone, Aeneas, Krishna, Jesus (a late

Nancy Evans Bush, M.A., President Emeritus of the International Association for NearDeath Studies, is a writer and retired pastoral counselor who had a frightening near-death experience in her late 20s. Reprint requests should be addressed to Ms. Bush at P.O. Box 9486, Bolton, CT 06043; e-mail: nanbush@att.net. 
tradition), and countless others. Despite their universality, these stories have been dismissed by most of the post-Enlightenment industrial world as the naive and credulous imaginings of pre-scientific people struggling to explain phenomena not yet approachable by rational means.

In our own decidedly scientific and technologically sophisticated time, medical achievements routinely enable survival of previously fatal conditions, producing not only enhanced lifespans but also the now-familiar descriptions of near-death experiences (NDEs), including reports of descent into frightening landscapes. An additional byproduct has been a welter of efforts by technologically sophisticated people struggling to explain phenomena not fully approachable by the rational means of science.

What is to be made of these explanations? Much discussion about NDEs has centered on the scientifically plausible precipitants of neardeath experiences, and on religious and philosophical explanations ranging from the literal to the metaphoric, from Satanic deception to deception by an illusory ego. However, no matter how one identifies the precipitant-limbic lobe excitation, effect of a drug, dissociation-the precipitant is not the experience. Similarly, the theoretical construct is not the experience.

Psychotherapist Alex Lukeman, in a different context, spoke of "the ego's encounter with the underlying unconscious and transcendent dynamics of the [Holy], and the accompanying destruction of traditional and habitual patterns of perception and understanding, including religious belief structures and socially accepted concepts of the nature of human existence and behavior" (A. Lukeman, Review of Encounter with the self, by E. F. Edinger, at http://www.frii.com/ tigrnest/encount.htm, created $3 / 25 / 98$, accessed $9 / 4 / 01$, italics added). I suggest that his words fit near-death and similar experiences.

The experience itself becomes a living memory. Whatever the precipitant and whatever the explanatory theory, the remembered experience-with its accompanying destruction of former patterns and concepts-will remain embedded as a vivid aspect of an individual's reality at the level of everyday functioning and must be dealt with in those terms. The pragmatic question is whether it will be dealt with well or badly, and that depends in large part on the information and resources available.

By an overwhelming margin, in both the popular and professional media, attention to near-death and similar experiences has gone to the 
affirming radiant experiences. Nevertheless, the people with perhaps the greatest stake in these questions-those who have had a frightening experience-remain the great underserved population, left largely to the interpretive devices of the general culture and their own imaginations. The topic is so laden with anxiety and judgmentalisms, it is no wonder that reliable information about these terrifying NDEs has been difficult to come by.

This article will not pursue the issue of ultimacy, whether the dark is as "real" as the light and whether terrifying experiences are, in that sense, "real." It is, rather, directed to the mundane, pragmatic level of the incarnational, physical world, where individuals struggling to understand the significance of a terrifying experience find the process of doing so quite real enough. The article considers what frightening near-death experiences mean to some individuals who live with such a memory and suggests preliminary approaches for dealing with them. It will also argue that by so quickly presuming "bad news," going to any lengths to avoid looking into the eyes of the so-called "negative" experience, we are all the losers.

\section{The Terrifying Experiences: Basic Facts}

Hard facts about frightening NDEs remain as few as the authors who deal with them. An admirably thorough review of the literature on frightening near-death experiences appeared in Gracia Fay Ellwood's The Uttermost Deep (2001), a wide-ranging exploration of the evidence for survival. Other books on frightening NDEs tend to subjectivity. The original work of Maurice Rawlings (1978, 1980, 1993), flawed by the fact that his purpose was clearly more evangelical than objective, was followed by publications from P. M. H. Atwater (1992) and physician Barbara Rommer (2000). The response of near-death experiencers to Atwater's work continues to demonstrate that her instincts about them are often right on target; nonetheless, her emphatic conclusions, especially about cause and effect, would benefit from documented evidence. Similarly, while Rommer's Blessing in Disguise is the strongest collection of frightening accounts to date, her conclusions are often unprovable and seem directed principally by a caregiving desire to offer reassurance.

Closer to objective are the work of Margot Grey (1985) in the United Kingdom and the smaller investigation of Bruce Greyson and myself 
(Greyson and Bush, 1992) over a ten-year period and our observations in the decade since then. The descriptive findings of our research provided the groundwork on which this present article depends. Basic facts about "less-than-positive" experiences, as Rommer delicately termed them, can be summarized quickly:

First, some people are terrified by a near-death experience. Although it may be described in the same general categories as radiant experiences-a tunnel, out-of-body experience, some quality of light, presences, ineffability, and so on-the way in which the categories manifest induces ontological terror, a profound and enduring fear at a deep level of the psyche.

Second, no hard evidence exists to document the proportionate frequency of frightening near-death experiences. The widely varying published figures ( 1 percent to 22 percent; Bache, 1994) are based entirely on the comparative numbers of reported radiant and frightening experiences, and on George Gallup's extrapolations (Gallup and Proctor, 1982) based on the numbers of people who have come close to death.

Third, the Greyson-Bush (1992) study distinguished three general types of frightening NDE. Grey's (1985) study found parallel patterns, although she considered the Void a characteristic of some experiences rather than a separate category. In the most common type of frightening experience, which Kenneth Ring (1994) has aptly called "inverse," the descriptive contents parallel those of radiant NDEs-light, presences, knowledge, landscapes-but are perceived by the individual as very frightening, an alien reality out of control and alarming in the extreme. A second type involves perceptions of utter emptiness, ultimate aloneness, and nonexistence. A third type of frightening experience is the prototypical "hellish" encounter, described in terms of loathsome settings, threatening entities, and various accouterments of the traditional Hell, marked by perceptions of impending judgment and torment. Rommer (2000) has described a fourth variety in which the person is deeply disturbed, even terrified, by the life review. Because of its emphasis on judgment, this type might be considered a subset of the hellish experience, or it may constitute, as Rommer believed, a unique type.

Fourth, the experience types are not always static. Sometimes surrender or a more detail-rich event (a seemingly "longer" duration) leads to transformation into a radiant experience; sometimes not. Sometimes a plea for rescue (to God or to a saint or familiar individual) ends the fear or transforms it; sometimes not. 
Fifth, a frightening NDE may produce long-lasting emotional trauma. Kimberly Clark, whose experience as a clinical social worker and head of the Seattle Friends of IANDS support group extends over two decades, noted years ago that, "Fear is pervasive: fear of the condemnation of others, fear of the experience itself, and fear of another terrifying NDE. Subsequently, these near-death experiencers may feel increased vulnerability and anxiety" (1984, p. 254). Atwater effectively described the emotional context in which these experiencers live:

[T] here is a special kind of fierceness about them, or an empty fear, or a puzzled indifference, or an unstated panic. If they show emotion at all, it is usually tears. Many feel betrayed by religion. Many resent the endless banter on television talk shows about "the Light," all that warmth and love and joy exuded from those who seemed to have experienced heaven. (1992, p. 159)

Sixth, some strong but preliminary conclusion about the meaning of the NDE is made during the experience itself, although reasoning comes afterward. Because the experience is ineffable and all-absorbing, from within the experience itself there is nothing but experience. However, the very fact of emotional response during the event indicates that cognitive processing is operating, whether conscious or not. In other words, the pre-existing mental data banks are still available for the naming of any encountered entities-Jesus, angel, the Judges, God; people do not return with previously unknown nouns at their disposal.

Beyond these observations lies little but conjecture- - to which, let it be noted, this article is not immune.

\section{Making Meaning: Three Types of Response}

Writing in this Journal, Christopher Bache observed:

Survivors of frightening NDEs are doubly alienated in our culture. First they must manage the general failure of our society even today to accept the reality of their experience. Second, and more importantly, while the majority of NDErs report basking in divine light, they were taken to hell, or at least to its doorstep. How could they not take this as a devastating commentary on their life? How could they not conclude that they were deliberately singled out for harsher treatment by some higher intelligence? This reaction is reinforced by theological interpretations of frightening NDEs. (1994, pp. 41-41)

Against this background, individual people awaken from a redefining experience and either repress or go about the long-term task of making sense of it. The immediate need is to find a denotative meaning, a 
definition of terms: What was that? One way or another, that question will lead to an evaluative process seeking comprehensibility. (It would be interesting to know the long-term effect of the first explanations they encounter when fully conscious, especially in people who have no ready vocabulary or context for the experience. A bewildered person might well grab for support from any construct that offers apparent certainty and higher purpose. This is purely speculative but deserves some exploration.)

Speaking of the difference between denotative and existential meaning, depth psychologist Lionel Corbett has noted, "It is useful to think of 'meaning' as the dispositional power of an event, or what it will cause us to think or do" (1996, p. 173). Following a terrifying near-death experience, then, what is its dispositional power-what do people tend to think, and how do they go about living their lives?

Personal observation over a good many years suggests at least three distinct types of response to the making of meaning in all near-death experiences, whether transcendent or terrifying, each meaning type linked strongly with the ways in which the people involved will go about living their lives. I do not claim that these three types of response are exclusive; however, they seem at least to be common. To the three discussed below, repression might be added in the case of terror, as Rawlings has repeatedly claimed. There is at present no reason to doubt that repression is common, but neither is there supporting data, as of course the experiences are invisible to investigation. Although it is likely that the response types apply to all categories of NDE, discussion here deals solely with frightening experiences.

\section{Response Type 1. The Turnaround: "I needed that"}

The classic response to profound spiritual experience is conversion, not necessarily in the sense of changing one's religion but of turning one's life around. This is the original meaning of "repent," the Greek metanoia, meaning "to turn around." In colloquial terms, the response is probably what people mean when they say, "I needed that."

It is my impression that among the people whose NDE was terrifying, those who heal most quickly and satisfactorily (in their terms) are likely to fit this model-people who interpret their NDE as a warning, who are able to connect it with previous behaviors they identify as unwise or downright wrong, and who then find avenues by which to modify their lives in satisfying ways. This literalized meaning appears especially 
among people who, having described their experience as explicitly Helllike, have taken a concretistic attitude toward it:

I was being shown that I had to shape up or ship out, one or the other. In other words, "get your act together," and I did just that. (Rommer, 2000 , p. 46)

I too am not afraid to die now, because I made sure where I'm going when I die. I was a good person when I died, but being good will not get anyone to heaven. (John 3:16).... My priorities changed and ... there is definitely a place called hell. After my experience, I could not talk about it. I did not want people to know that I had gone to hell. I got out the Bible and really studied.... Some people may just want to laugh this "hell business" off, but as real as this letter is, so is that place. (L.P., personal communication, August 16, 1982)

The feeling I got was redemption. Hell was the place I was bound for, but not a place that I have to go now. (Rommer, 2000, p. 50)

Here is the classic "saved" scenario of self-perceived bad behavior or attitudes, warning, and a meaningful resolution as the individual significantly changes his or her life pattern. Not all such accounts are from people with a religious background. Some readily admit to earlier antisocial behaviors-heavy drinking, drug use, violence, or trouble with the law-while others describe a more internalized history of quick temper, selfishness, or problems forming relationships. Among contemporary near-death experiences, the best-known of this type is no doubt that of Howard Storm (2000), self-described as an angry, hostile atheist before a harrowing experience that transmogrified into one of affirmation and transcendence. Storm, who now describes himself as a happier man and a better husband and father, left his academic position and went on to a career of full-time parish ministry in the United Church of Christ.

Movement toward some religious community is a common report in this group. Clark, who, after Rawlings, was among the first to comment on hellish experiences, observed, "All the people I know who have had negative experiences have become Bible-based Christian... They might express it in various sects. But they all feel that they have come back from an awful situation and have a second chance" (cited in Flynn, 1985, p. 85).

Storm's choice of denomination may be less than typical, as United Church of Christ is perhaps the least authoritarian and most liberal of the mainstream social action Protestant denominations, emphatically not holding to a "hellfire and brimstone" theology. However, whatever 
their religious beliefs, if any, before the NDE, it does appear that a significant percentage of people reporting an explicitly hellish experience may go on to find a spiritual home in the more literal-minded, conservative religious communities. Fear may remain a powerful influence, but within those groups they will find sanction for it, and a way out:

I've stopped drugs, moved back to Florida, and now I'm in Bible college. I used to have a casual attitude toward death, but now I actually fear it more... . So yes, it was a warning. I was permitted another chance to change my behavior on earth. I've taken the fear of death and given it to the scriptures. (Rommer, 2000, p. 43)

The role of fear in conservative religious groups has been well documented (Marty and Appleby, 1992; Rawlings, 1978; Spong, 1992). Whatever one's personal beliefs about the subject, it is worth noting that for persons who come to conservative religion with a deeply embedded fear-from an NDE or any other source-the theology offers legitimization: the person is not hallucinating, not mad; there are, in fact, malevolent external forces at work; and there are ways to prevail against them. Within a conservative religious group these experiencers can find welcome and support: affirmation of a truth in their experience and a language in which to talk about it, a theology within which to find an explanation of what happened to them and a way beyond it, and a social community prescribing definite rules about how to live in the world so as to avoid another such encounter. What seem to outsiders like narrowly drawn social and theological boundaries, some frightened experiencers identify as safety nets promising, after all, the Heaven that eluded them earlier.

\section{Response Type 2. Reductionism: "It was only..."}

For the most part, reductionism in the field of near-death studies has been the province of investigators looking for the possible physical or psychological sources of NDEs. It is a common attitude in the matter-offact scientific community accustomed to the certainty of hard evidence and replicable data. Obviously, the work of those investigators is significant, especially for the healthcare professions, and in clinical terms may prove quite adequate to identifying meaning.

As a response to the question of meaning in the life of a single individual, however, reductionism can be problematic. In this case, what reductionism does is to push the experience itself, and its mystery, into the background in favor of focusing on a more familiar-and therefore 
less troublesome - precipitant. Corbett described this kind of disavowal as the "defense [that] allows one to repudiate the meaning of an event which does not fit into a safe category ... [and to] treat the event as if it did not matter" (1996, p. 35).

However, it is not only investigators who find physically-based explanations appealing. Some experiencers, too, find material (external) theories more palatable than efforts to make meaning (self-examining). The near-death experience of a young woman in New York City included first loving, then frightening elements. Although she reported that her life has changed significantly and positively since the experience, she has concluded:

There is a universe of people who have had experiences like mine. They have weekly Internet chats and meetings, and they write books with "light" in the title: Saved by the Light, Lessons from the Light. They have their own shorthand, talking about NDEs (near-death experiences) and OBEs (out-of-body experiences). Their websites play plinky New Age music, and some talk about angels and aliens. My feelings about these people? Excuse me while I look around for Mulder and Della Reese.

There are actual rational explanations for what I experienced. British researcher Susan Blackmore says ... [it is endorphins and cortical activity]. In the 1930s, a University of Chicago scientist, Heinrich Kluver, $\mathrm{PhD}$, determined that ... [it is anoxia]. University of Chicago neurobiologist Jack Cowan, PhD figured out that ... [it is neural activity in the dying brain]. It's all very scientific. (Ingall, 2001)

As best one can judge from the tone of her article, the young woman seemed quite aware of the positive effects of the experience on her life and untraumatized by its disquieting aspects. Her conclusion was that, based on the scientific evidence, the experience had no particular meaning except to indicate that actual dying will not be all that bad.

A different response entirely is that of a man who has for more than ten years been telling groups about his radiant NDE and exploring its spiritual and evolutionary significance. He recently had a second experience, in which he felt himself to be the prey of gigantic, brightly colored but sinister and threatening geometric forms that rushed at him with uncanny force and speed. Its effect, he has said, was to "wipe out" the meanings he had ascribed to his earlier NDE, leaving him with a deep-seated pessimism and terror of dying.

The experience was so horrifying that he has consulted an attorney about bringing a malpractice suit against his physician and the hospital. He has no interest in exploring this event or why his reaction to 
it is so different from the first; no amount of argument or reassurance based on his earlier, radiant NDE could ease his fear or his rage. In Corbett's terms, the experience decidedly "does not fit into a safe category" and must be repudiated. Hearing that certain drug reactions commonly include perceptions of visual forms like those he found so frightening, he found a possible way out: The second experience was "only a drug reaction" (A. S., personal communication, August 13, 2001).

Kenneth Ring has put forward the generally semantic argument that "such experiences-though highly real-are not true NDEs as such but are essentially emergence reactions to inadequate anesthesia ... further intensified by initial resistance and fear" (1994, pp. 20-21). This could be an appropriate conclusion about causation, but it begs the question so far as meaning is concerned, and seems a fair example of Corbett's reductionism as a "defense [that] allows one to repudiate the meaning of an event which does not fit into a safe category."

The experience remains. To the individual, living with something that looks like an NDE, acts like an NDE, and talks like an NDE, "It's only a drug reaction" may provide a temporary buffer that, at least in the short term, masks questions and anxiety but does nothing to help resolve them. It is not surprising that this experiencer-not yet able to defuse the hidden threat he remembers from within the second experience or to recapture confidence in his first-remains very fearful.

\section{Response Type 3. The Long Haul: "What did I do?"}

While the "conversion" experiencers find meaning in the relationship between their faith and their NDE, and reductionism offers at least a minimal satisfaction for others, a third group has identified no comprehensible or acceptable meaning in the encounter. Especially following experiences of the Void but cutting across other types also, these are people who, years later, may still struggle with the existential implications of a frightening NDE.

The following quotes are from letters in my files:

I had an experience which has remained with me for 29 years... Over the years I read various books on life after death and everyone seemed to have good experiences.... It has left a horror in my mind and I have never spoken about it until now. (D.P., personal communication, undated)

For twenty-six years I have been plagued by a fear of death [following an NDE].... As a result of this traumatic experience, I developed anxiety attacks, depression and feelings of depersonalization. These emotional problems grew into a generalized phobic response problem 
(agoraphobia). Although I have overcome these problems for the most part, I still harbor some fears about death. (C.B., personal communication, October 16, 1982)

For some reason, [31 years later] all the memories are back and vivid, including the incident. It's like living it all over again, and I don't want to. I thought I had it all resolved and in its place, but I'm having a really bad time trying to put it away this time. (J.E., personal communication, undated)

I have experienced some serious problems this year [including] depression. The weight of my unresolved NDE experience seemed, at least at times, to deplete the energy required to deal with current situations. (C.W., personal communication, October 28, 1992)

Based on conversations and correspondence with individuals in this group, my impression is that these are typically articulate people haunted by the existential dimension of the event and searching for an explanation that is both intellectually and emotionally grounding. Intellectually unable to accept a literal reading of the event, they also find reductionist explanations generally inadequate, as they assign a cause but do not address the question of meaning. Of the three groups, perhaps none has worked harder to find resolution. Their struggle is to find a way in which the encounter can make sense without destroying them (which is to say, their trust in the workings of the world) in the process.

Psychological exploration alone seems inadequate. More than the other experiencer groups, these people mention having been in therapy, some of them for many years. Without better data, it is not possible to say whether this indicates anything other than openness and financial means. Their caregivers, for the most part, have been unable to reach the "real" issues: There are too many stories of medications prescribed to mask the questioning; of therapists who will not address the matter, or who leave the client feeling blamed, or who romanticize spirituality and cannot deal with its dark side; and of clergy who have no idea what to say or who reject the experience outright.

The religious element of their experiences is often an absence:

I was filled with a sense of absolute terror and of being past the help of anyone, even God. (C.B., personal correspondence, July 15, 1981)

Nobody was there, not even God. (B.T., personal correspondence, April $4,1983)$

I expected the Lord to be there, but He wasn't. There was no God.... I called on God and He wasn't there. That's what scared me. (Rommer, 2000, p. 53) 
Overwhelmingly, their questions include some variant of, "What did I do to deserve this?": What is the truth about existence? What's wrong with me? What is there that I can't identify about myself, that this should happen? What are the rules, if the rules I lived by don't work? Not for a long time, if ever, do they lose their fear of death.

\section{Going Behind the Story: The "Why?" Question}

The most deeply persisting question, of course, is "Why?" Why do some people encounter an affirming radiance and others say they "went to hell"? (And behind the scenes, the unvoiced question for all of us, "... and would that happen to me?")

The plain fact is that nobody knows. Theories abound, but nobody knows absolutely why one person's experience is gloriously life-affirming and another's leads to angst-filled years of turmoil. The question has haunted humanity for thousands of years and will in all likelihood continue to do so, this article notwithstanding. Some observations about primary assumptions, though, may be useful.

\section{Heaven and Hell}

It goes without saying that whatever the "Why?" of near-death experiences, one reason for their profound social impact is their similarity to traditional descriptions of Heaven and Hell: "New proof of ...," as the tabloids are fond of saying. Turning this concept at an angle, it seems probable that the very concepts of Heaven and Hell originated in the near-death and similar experiences of preliterate times, whereupon the power of those experiences - stories told and retold-rooted them in the very foundations of religious and moral teachings through the ensuing millennia.

One cannot simply expunge the influences of thousands of years of teaching and storytelling. Today, the tinge of centuries accompanies these experiences: We assume in our bones that people get what they deserve. Truth to tell, for a great many contemporary people-people with no belief in a literal Heaven or Hell and a marked distaste for the concept of "divine judgment" - the immediate assumption about frightening near-death experiences is that they are "negative," or a warning based on lifestyle, or the reflection of some characterological deficiency on the part of the experiencer (ego or $\sin$ ). In other words, they make a judgment. 
Although no clear evidence indicates why some individuals plumb the depths of spiritual experience while others find themselves at the heights, two small but curiously interesting details mark a difference in the approach of investigators to radiant experiences and those considered "negative."

First, with radiant experiences, the reported psychological aftereffects-loss of materialism and fear of death, capacity for unconditional love, and so on-have elicited widespread publicity and admiration; simultaneously, the literature reveals little curiosity about the personal characteristics that might serve as qualification for a radiant experience (perhaps its presumed universality has eclipsed curiosity about why it happens to particular people). On the other hand, with frightening experiences, the situation is exactly reversed: Here, where one finds almost no evident curiosity about aftereffects, there is an intense scrutiny of the life patterns and (presumably flawed) beliefs, mental status, and ego issues that are supposed to have led to these experiences.

These assumptions are widespread. Atwater wrote, "This type of [unpleasant and/or hell-like experience] ... is usually experienced by those who seem to have deeply suppressed or repressed guilts, fears, and angers, and/or those who expect some kind of punishment or accountability after death" (1992, p. 156). Similarly, Rommer declared, "There are three main reasons why [a frightening experience] may occur. First, it may occur in order to challenge the person to ... reevaluate ... in order to make midcourse changes in direction. Second, [it] may occur if the person has a ... less than loving, or fearful mindset just immediately prior to the event. Third, if one grows up with negative programming expecting hellfire and brimstone, then that is what... he or she will be given to experience" (2000, p. 26).

The global Atwater assessment does not recognize that everyone, even those who report dazzlingly transcendent experiences, has "deeply suppressed or repressed guilts, fears, and angers," nor does it acknowledge that people self-described as guilt-ridden, fearful, and angry have reported glorious accounts. It is not enough.

Similarly, Rommer's confident assertions in the absence of testable data seem, like Atwater's assumptions, largely the triumph of personal belief over objective evidence. Certainly experiencers are often challenged to make life changes, and mindset may reasonably be hypothesized to have influence (though this begs the question of why suicide attempts sometimes produce experiences of glory); however, unprovability is a significant problem when claiming that experiences occur in 
order to effectuate a turnaround, or as a result of the person's emotional status.

The probable truth within these and similar conclusions about the "why" of a frightening experience may be far subtler than these broadbrush declarations.

\section{Religious Belief}

The commonly reported correlation of experience type with religious belief may or may not hold up to thorough, unbiased, documented investigation; to date, that investigation has not been done. Although some individuals who believe in a punitive and vengeful God have reported terrifying NDEs, others with that same conviction encountered radiance; while people with no religious indoctrination, or with lifelong belief that "God is love," have had utterly terrifying experiences.

In short, although it seems reasonable to assume some relationship between belief and encounter, the argument may be more logical than true. The range of bardos described by The Tibetan Book of the Dead (Evans-Wentz, 1957) coupled with the varieties of encounter in Stanislav Grof's (1975, 1994; Grof and Grof, 1980) perinatal matrices (see section II, The Numinous Experience, below) indicate strongly that the "belief $=$ encounter" argument is an oversimplification.

\section{Ego Resistance}

At a different level is the argument, basic in the spiritual and psychological literature, that a frightening NDE merely reflects the failure of an individual ego to yield to the experience. The question is not, really, whether this is true, as evidence exists in abundance across centuries and continents to support the idea. However, concerning life during and after a frightening NDE in the largely monotheistic West, a number of issues come immediately to mind. As Grof $(1975,1994)$ has repeatedly pointed out:

It is now understood that these are experiential states ... of quite regular occurrence when one is facing biological death.... Instead of representing bizarre and ultimately useless pieces of knowledge, the data about the hells and heavens can prove to be invaluable cartographies of strange experiential worlds which each of us will have to enter at some point in the future.

.... [A]voidance and reluctance to surrender are considered two of the major dangers the dying person faces. (Grof and Grof, 1980, pp. 15 and 20) 
To lessen those dangers was the purpose of the rituals associated with the Egyptian Book of the Dead (Budge, 1967/13th century B.C.), The Tibetan Book of the Dead (Evans-Wentz, 1957/11th century), and the medieval European Ars Moriendi (Rainer, 1957/15th century). Their function was to warn those caring for the dying not "... to allow the individual to use denial and die unprepared" (Grof and Grof, 1980, p. 20), but further, "to allow the deceased to recognize as opportunities for liberation the states with which he has already become acquainted during his [spiritual] practice" (Grof and Grof, 1980, p. 18).

It is worth noting that we exercise that same denial by "avoidance and reluctance to surrender" to exploration of the dark side of spirituality. In a society with no tradition of Ars Moriendi or Book of the Dead, and which has devalued and increasingly deinstitutionalized the sources of such information, it is highly likely that we go absolutely unprepared for a terrifying spiritual experience, whether at the time of death or long before. As long as frightening NDEs and similar experiences are shunned and denigrated, their "invaluable cartographies" remain unavailable.

One thing experiencers know about, however, is attitudes. When the subject of frightening NDEs does appear in the contemporary literature, it is common to find the implication that with a terrifying experience, the individual "should have" given in to it. This assumes not only that the person knows this beforehand, but that the decision can be somehow volitional from within the experience. Perhaps people with lucid dreaming ability can achieve this; however, the likelihood is that most NDEs and similar experiences are not under the individual's conscious control. A parallel implication running through much of the literature is that what is called (perhaps erroneously) ego death bestows a moral superiority, as if it were a matter of spirituality-climbing (" $\mathrm{My}$ consciousness is higher than your consciousness"). A number of experiencers, in conversation, have noted a strong air of judgmentalism in this regard. While those are irritants, the far more important issues about ego surrender are cultural and developmental.

\section{Development and Culture}

Since its inception, Western society has placed a high value on ego, personal achievement, the value of the unique individual. For 3,000 and more years, its major religious traditions have been grounded in concepts of personal identity and personal relationship. The very name of the ancient Yahweh translates roughly as a thunder of 
identity-IAm That IAm-and Christianity has been described as "the most psychological of all religions because of [its] emphasis on the inner development of the individual and the important role which it assigns to the ego as the bearer of consciousness" (Sanford, 1970, p. 218).

This is not to be dismissed lightly. In this context, so deep as to be unnoticeable, the threat of no "I-am," of nonbeing, is the engine driving many developmental crises. Probably few students in introductory psychology classes, reading of egocentricity in early childhood development, realize this, or that they are studying spirituality. Yet here is how the renowned Jungian scholar Edward Edinger put it:

In the early stages of psychological development, God is hidden-in the cleverest hiding place of all-in identification with oneself, one's own ego.... This notion of the divine spirit imprisoned in matter, hidden in the darkness of the mind, represents the Self hidden in identification with the ego.... This is the central theme: Psychological development in all its phases is a redemptive process. The goal is to redeem by conscious realization, the hidden Self, hidden in unconscious identification with the ego. (1972, pp. 102-103)

As Edinger noted, psychological development is a process, beginning with that first uroboric oneness and having as its goal a mature arrival, eventually, at a second naivete that recognizes the shared essence but without the immature arrogance. However, the development of a healthy ego is the task of the early years, and its adequate functioning makes life in society possible during the ensuing 40 or more years. The goal is to redeem, not to blast the ego to smithereens. It seems highly likely that the experiencers of group three are struggling with just such a catastrophic occurrence. Corbett has observed:

What happens in psychotherapeutic practice is that...the self gradually realizes that it is not who it thought it was, and increasingly realizes its continuity with Mind.... But to try prematurely to let go of a fragile self... is to court emotional disaster. $(1996$, p. 63)

Elsewhere he noted:

Even the most sublime wisdom is of no value if it is given at the wrong time, to the wrong person or in the wrong manner.

We may need to make a personal choice between Buddhism's assertion that there is no self in the sense of an entity (anatman), and the Judaeo-Christian and psychological assumption that such an entity exists.... [In the former] there is no self as a separate entity distinct from the totality of consciousness.... [Each experience] must be allowed to fall away as a stage towards realizing the illusory nature 
of ego-Self separation. Or, if one prefers the idea of relationship, one may choose to savour each numinous experience as a way of deepening the ego's relationship to our true centre and identity. (1996, p. 159)

In short, no road is the only road. People with an Eastern understanding or a particular temperament may well find fewer conceptual hurdles in "letting go." For others, the least one might expect is respectful acknowledgment of the true character of Western experience that would find value in a struggle of cosmic importance.

\section{The Descriptive Fallacy}

The literature of contemporary near-death experience, like the oral tradition of prehistory, reveals widespread fascination with the stories themselves, with the narrative details of their landscapes and encounters. This has certainly been the case with experiencers' personal accounts, and the first generation of professional publications has dealt largely (and understandably) with descriptive studies. It has often seemed, however, as if the description is the experience, its history a single line of NDE accounts traced back to Er in Plato's Republic and forward to an evolutionary role in an expanded global consciousness.

One ironic result is a curious similarity of approach at both poles of right and left-religious fundamentalists at one extreme and secular examiners at the other-both dealing only with the descriptive level, discussing it in terms of physical reality.

The religious fundamentalist end of literalism assumes that NDE accounts describe real, external objects, persons, and events-which, to the extent they accord with doctrine, are believed wholeheartedly. At the reductionist end of the rope (with which, we believe, both may hang themselves), the discussion also deals with NDE accounts as reflecting some aspect of the natural world-but, from the materialist view, the described events are manifestly impossible and thus not one whit believable.

Absolute faith or absolute delusion? While the focus on description has been essential as an introduction to the subject field, it is the nature of introductions to be superficial. I will make the case here that both positions are missing the point, and that a different approach is more likely to be of assistance, at least to the third group of experiencers described above. 


\section{Deepening the Context: Defining Terms}

The same impulses of the human psyche that led to the Eleusinian Mystery School and Methodism have been witnessed in recent years in the Western world by a hunger for a sense of meaning and purpose; by surging interest in Eastern traditions, Native American beliefs, and metaphysics; and by the tidal wave of books and workshops on what one might call generic spirituality. Over much the same period came all "the books with 'light' in their title," the near-death experience literature.

These books and workshops have nourished untold numbers of searching people. However, two key points, well known in religion and transpersonal studies but frequently overlooked on the contemporary scene, deserve attention: First, like the universe itself, the world's sacred literature encompasses themes of darkness as well as light. And second, it is the nature of religious language to be symbolic, not literal. Tracing these connections leads toward some potentially helpful ways of approaching frightening NDEs.

\section{The Unwelcome Dark}

To Saint Paul is traditionally attributed the observation, "It is a fearful thing to fall into the hands of the living God" (Hebrews 10:31), echoed in Corbett's words, "It is time to acknowledge that the divine manifests itself to individuals in unique ways, some of which cause great suffering" (1996, p. 2). Or, as metaphysician William Carl Eichmann observed, "The spiritual quest is dangerous, just as the books say. Seeking truth means experiencing pain and darkness as well as the clear white light" (1991, p. 134).

Freed from the seeming strictures of orthodoxy but consequently limited by ignorance of deep tradition, relatively few of today's authors on generic spirituality have addressed this issue, which is familiar in the world of religious community and monasticism. The many profound experiences of St. Teresa of Avila are a case in point. From one of them comes this excerpt:

The entrance, I thought, resembled a very long, narrow passage, like a furnace, very low, dark and closely confined; the ground seemed to be full of water which looked like filthy, evil-smelling mud, and in it were many wicked-looking reptiles. At the end there was a hollow place scooped out of a wall, like a cupboard, and it was here that I found myself in close confinement. But the sight of all this was pleasant by comparison with what I felt there... I felt a fire within my soul the 
nature of which I am utterly incapable of describing. . . The fact is that I cannot find words to describe that interior fire and that despair which is greater than the most grievous tortures and pains... There was no light and everything was in the blackest darkness. (cited in Bache, 1994, pp. 42-43)

Teresa, in a supportive community and accustomed to the language and breadth of religious experience, was able to integrate her many encounters. Hers was a very different context from today's.

In the prologue to the excellent collection of essays titled Meeting the Shadow, editor Connie Zweig illustrated a pervasive contemporary belief:

I had believed, with a kind of spiritual hubris, that a deep and committed inner life would protect me from human suffering, that I could somehow defiate the power of the shadow with my metaphysical practices and beliefs. I had assumed, in effect, that it was managed, as I managed my moods and my diet, with the discipline of self-control. (Zweig and Abrams, 1991, p. xiv)

Later in the same book she noted,

Seekers are often led to believe that, with the right teacher or the right practice, they can transcend to higher levels of awareness without dealing with their more petty vices or ugly emotional attachments. As Colorado journalist Mark Barasch puts it: “Spirituality, as repackaged for the new age, is a confection of love and light, purified of pilgrimage and penance, of defeat and descent, of harrowing and humility." (Zweig and Abrams, 1991, p. 130)

Here is a clear echo of Carol Zaleski's often-quoted comment, "[G]one are the bad deaths, harsh judgment scenes, purgatorial torments, and infernal terrors of medieval visions; by comparison, the modern other world is a congenial place, a democracy, a school for continuing education, and a garden of unearthly delights" (1987, p. 7). And as her Otherworld Journeys (Zaleski, 1987) so brilliantly illustrated, the range of such experiences throughout the years has been far broader than the near-death literature in general would admit.

\section{The Numinous Experience}

In the religious vocabulary, what individuals are encountering in their near-death experiences is what Rudolf Otto termed the numinosum, the Holy. The encounter he called the mysterium tremendum:

It may burst in sudden eruption up from the depths of the soul with spasms and convulsions, or lead to the strangest excitements, to 
intoxicated frenzy, to transport, and to ecstasy. It has its wild and demonic forms and can sink to an almost grisly horror and shuddering. It has its crude, barbaric antecedents and early manifestations, and again it may be developed into something beautiful and pure and glorious. It may become the hushed, trembling and speechless humility of the creature in the presence of-whom or what? In the presence of that which is a mystery inexpressible and above all creatures. (1958, p. 12)

Compare that description with the levels of consciousness described by Grof in his extensive therapeutic research with holotropic breathing and psychedelics:

\begin{abstract}
Modern research focusing on [nonordinary states of consciousness] brought unexpected new insights... [that] people can encounter an entire spectrum of unusual experiences, including sequences of agony and dying, passing through hell, facing divine judgment, being reborn, reaching the celestial realms, and confronting memories from previous incarnations. These states were strikingly similar to those described in the eschatological texts of ancient and pre-industrial cultures.... [S]tudies of near-death states... showed that the experiences associated with life-threatening situations bear a deep resemblance to the descriptions from the ancient books of the dead, as well as those reported by subjects in psychedelic sessions and modern experiential psychotherapy.

It has thus become clear that the ancient eschatological texts are actually maps of the inner territories of the psyche encountered in profound [nonordinary states of consciousness], including those associated with biological dying. (1994, p. 24, italics added)
\end{abstract}

Two vocabularies, one universe. "The psyche," wrote Corbett, "is the essential medium for religious experience" (1996, p. 2).

\title{
Making Connections: Archetype and Symbol
}

What has been largely missing from discussions about near-death experiences is the explicit acknowledgment that because these experiences are ineffable, they have no precise denotation. Like the Sacred, they have many images but no physicality. It is exactly for this reason that the language of science has difficulty (one could say, impossibility) with them.

The voice of the experiencer's account is not that of the research report or even journalism, with its characteristic objective voice; rather, these are personal narratives, stories-a universal form (characters, setting, plot) for the carrying of messages. 
Listen to experiencers analyze their accounts, and you hear the language of poetry: simile ("It was like, it was as if...") and metaphor ("It was ...”). Their stories, as linguist Regina Hoffman (1995a, 1995b) has noted, are told in layers, because no single descriptive element is big enough. The situation is analagous to that of conceptions of God, because no one denotation can encompass the entirety: Creator, Almighty, Most High, Shepherd, Rock, Father, Mother, Holy Spirit, Source, Ground of Being, King, Living Water, Other.

Because this is an age accustomed to science more than religion, to journalism more than literature, to denotation more than connotation, and to "reality" more than the imaginal in arts and entertainment, it trusts those things that are "up close and personal," seen directly rather than out of the corner of the eye. This is not an age that quite knows what to do with symbol. ("Why can't they just come out and say it?") But as a map is not the territory, so NDEs are not the territory; they are maps written in symbol. They point to a "territory" beyond the capability of language to describe, and beyond the ability of physical vision to image. They point in one great general direction, but not down a single roadway. And so, the only route to them is through the same means as any ineffable experience: through imaginal language and symbol and archetype.

A rabbinic legend tells us that the first Torah was written "in black fire on white fire.... And that furthermore and at the same time there is a whole other Torah written in white letters in what we sometimes think are the spaces between the black letters" (Kushner, 1977, p. 12). It takes a long time, learning to read that hidden material; yet in all encounters with the Holy, including near-death experiences, much of the deepest meaning rests in those white spaces between the black letters of written accounts.

This is, admittedly, the stuff to drive geologists and chemists mad. In fact, the difficult truth is that some realities wiggle, as physicists discovered last century. It is one reason "spirituality" is so often perceived as totally ungrounded. The elements of spiritual experience, though, may be no more elusive than, say, quarks. We look for patterns, and find them everywhere. The following comes from a recent online review of an annual poetry anthology:

The need for coherence appears to be basic, perhaps even neurological. Science has proved the human brain strives to find a pattern, an order, a meaning in chaos. What isn't coherent, we strive to make so. It satisfies us. Thus, before settling for separate, unconnected pieces... we will look hard for connections. (J. Houlihan. " $\mathrm{I}=\mathrm{N}=\mathrm{C}=\mathrm{O}=\mathrm{H}=\mathrm{E}=\mathrm{R}=$ 
$\mathrm{E}=\mathrm{N}=\mathrm{T}$ : How Contemporary American Poets are Denaturing the Poem," http://www.webdelsol.com/LITARTSBoston_Comment/)

In NDEs as in poetry, finding meaning is a matter of making our connections, and in developmental terms, the more connections we are able to make between ourselves and the rest of existence, the more developed and inclusive will be our understanding. The vocabulary of archetype and symbol provide a framework for discussing the question of meaning-making with near-death experience.

\section{Archetype}

In what could otherwise be the chaos of the psyche, the connectionmaking function is served by the concept of archetypes, so named by Carl Jung and more recently defined by Corbett as:

fundamental organizational levels which determine the structure of the personality. These principles act as fields of information which are usually unconscious themselves, but become conscious to varying degrees.... This process involves the accretion of personal experience around an organizational core.... When an archetype is felt relatively directly within the psyche, its effect is numinous and it is felt as Other. Phenomenologically there is no difference between these [archetypal] experiences and those described as the experience of spirit in the religious literature... Because the terminologies of psychology and theology differ when they describe archetypal experiences, a pervasive but erroneous sense has arisen that religious and psychological approaches to the person are describing factors that are different in kind. This split has been fostered by the fact that our culture has partitioned off religious experience as if it had nothing to do with normal human development. We are not used to the idea that elements of the divine are important in forming the very structure of the mind." (1996, p. 60, italics in original)

At its simplest, the archetypal connection may be the "That's me!" identification with a fictional character, or a strong and unexplainable feeling of attraction to a theme or even a landscape. At Tillicum Village in Puget Sound, a Native American dance troupe dances the Sasquatch legend, an elusive dark beast, shadowed and not-quite-identifiable, appearing and vanishing, then reappearing among the great trees. For some veterans of frightening NDEs, the performance has provided a powerful and freeing sharing of a nameless truth that is the archetypal ground of their experience.

Like Sasquatch, the dark beast, the archetype of the hero's journey has enormous healing potential for these experiencers. Here are all the 
stories of descent into the Underworld: the challenges by terrifying entities with great powers; the need for courage and resourcefulness in facing them; the finding of the apple, the fleece, the ring-the symbolthat is needed for resolution; the struggle to return home. Just as the Biblical story of Eden reflects the archetype of the earliest phases of human and individual development into consciousness, so the constellation of elements in the hero's journey forms the template of the dark NDE. (For an in-depth discussion of Jung's principles as they apply to NDEs, see Grosso, 1983.)

Two points are especially necessary here. These stories are forms of the great myth-the narratives that never happened but are always true - of the hero's journey, not the loser's, or the damned's. They demand integrity and persistence from the one who is called; they are never easy, but always worthwhile. This is worth remembering before making the rush to judgment. Second, what has been lost over the centuries, at least in the monotheistic traditions, is the idea of the gift within the experience. Whereas the ancient stories hold out a treasure at the depths of this journey, we have truncated the archetype by expecting only torment and punishment. The experiences are incontrovertibly frightening; but it is our doing that they are labeled "bad." It is time, once again, to look for the richness that lies within these extraordinary encounters.

With this understanding clearly in mind, it is possible to look at NDEs and similar experiences from a fresh perspective.

\section{Sign or Symbol}

It is no secret that eras, like tectonic plates, are shifting and colliding around us. As the Newtonian worldview of solid "stuff" and hard edges has been forced by particle physics to retreat from its previous hegemony, entire new ranges of thought have been emerging. If there is one thing held in common by the authors cited in this article, it is their awareness that a profound reconceptualization has for some time been reshaping our sense of ... everything. As expressed by theologian Walter Wink, here is our context:

We are living at the juncture of two ages, when a senescent worldview is contending with its upstart successor and the boundaries of what seems possible liquefy.... The new age dawning may not "believe in" angels and demons the way an earlier period believed in them. But these Powers may be granted a happier fate: to be understood as symbolic of the "withinness" of institutions, structures, and systems. 
People may never again regard them as quasi-material beings flapping around in the sky, but perhaps they will come to see them as the actual spirituality of actual entities in the real world. Even if we no longer endow them with human personalities and qualities, we can understand them to be as real as anything: the invisible, intangible interiority of collective enterprises, the invariant, determining forces of nature and society, or the archetypal images of the unconscious, all of which shape, nurture, and all too often cripple human existence. These mighty Powers are still with us. They are not "mere" symbolsthat too is the language of the old worldview that is passing, for we now know that nothing is more powerful than a living symbol. As symbols they point to something real, something the worldview of materialism never learned to name and therefore never could confront. (1986, pp. 172-173)

But how to name them, and how confront? If the elements of neardeath experiences were as easy to read as signs, like computer icons, it would be possible simply to hand out a list: Here are the pieces; here is their meaning. Inconveniently, that is not the case. Interiority works not through signs (which relate to things) but through messages carried in symbol.

Sanford said simply, "Conscious minds think conceptually; the unconscious expresses itself in symbol" (1970, p. 22). Corbett said, "The simplest way in which the Totality makes itself known to the ego is by means of an image" (1996, p. 45). Edinger made the important observation that a symbol is "an image or representation which points to something essentially unknown, a mystery" (1972, p. 109). He expanded: "[I]t is the symbolic image, acting as releaser and transformer of psychic energy, which lifts the instinctive urgency to another level of meaning and humanizes, spiritualizes, and acculturates the raw animal energy" (1972, p. 114).

Some years ago, a woman told an interviewer of her powerful life review, in which she sat in a rocking chair with a much-loved and long-deceased aunt, examining her life. Asked whether she had encountered any judging presence, she replied no, that she would have been too frightened. But then she paused suddenly, considered, and finally said, "Oh! Oh!-God in an aunt suit" (R. Newsome, personal communication).

The symbol presents and must then be conceptualized. In other words, before an NDE or similar experience can be humanized, spiritualized, and acculturated, some probably quite ordinary human individual must be able to translate its contents. But if the referents are not "quasimaterial beings flapping around in the sky," what are they? The task is 
to look at the images of heaven and hell, as we have at the atom, and ask: well, if it is not what we thought, then what is it?

The nature of this struggle was the subject of a conversation I had some years back with author and Biblical and Jungian scholar Wayne Rollins, then head of the graduate department of Religious Studies at St. John's College in Massachusetts. He summarized:

Personified with gaping throat and jaws, devouring, or as emptinessthese experiences read like dream material. This is Erikson's "ego integrity": they are signposts of invitation to true maturity, the promise of integration precipitated by despair. Fear is psychological, but anxiety is ontological, Kierkegaard's "dread." Ecclesiastes and "all is vanity"that's a canonical statement of ontological dread. The anxiety is objectless-ontological-from the threat of destruction, of non-being. It is indigenous to the human condition-Henley's "Invictus"-the anxiety resolved by discovery of his unconquerable soul. The crisis precipitates an answer to the problem of dread; it reflects one's unconscious state.

For some individuals, this is the first time they have confronted the issue of their own mortality at a deep level. Irrespective of any objective referent, the experiences are intensely meaningful, the promise of integrity precipitated by despair; and the fatalistic despair after the experience crystallizes the recognition so it can be dealt with. The experiences are crying for integration.

In the classical creeds, the descent to hell-that's not for nothing. It's recognition of the very real existence of evil, of emptiness, of Nothing as a real presence but not the end. It's very Joban, driven to recognize apparent evil, destruction, chaos. The presence of apparent evil does not mean the absence of God; that will come as a more mature recognition. This is not simple resurrection theology but resurrection symbolized, not literal but real, a deep recognition of the power of $\mathrm{Be}$ ing that overrides Non-Being, with integration as representing true maturity. (W. Rollins, personal communication, 1991)

Symbol piles upon symbol, the vocabularies of psychology and religion interweaving; and as this powerful analysis indicates, it is not only by "letting go" within the experience that integration is won; integration comes as a process afterward. Awareness of developmental and cultural issues at this level is surely called for in understanding the impact of frightening experiences and working through them, whether for ourselves or in the service of others.

\section{The Will to Resolution}

What can help a person understand a terrifying near-death or similar experience? Some day, a skilled and knowledgeable therapist will write 
more definitively about the techniques that can be helpful. Until that time, the suggestions offered here are based on almost 40 years of "been there, done that" and relentless exploration. It should be noted that where suggested approaches are religious in nature, they are based on several strands in contemporary theological scholarship and expand considerably beyond literal interpretations.

\section{Initial Response}

In the early days, months, and possibly years following a deeply frightening experience, it is important to tread lightly. The only recourse may be to buy time until the panic has subsided enough for cognitive processing around the event even to be possible. Hope need not be reasoned to be sometimes most important.

These points can be especially helpful:

First, there is absolutely no evidence that "Good people have good experiences and bad people have bad ones."

Second, there is some evidence, based on therapeutic work in other disciplines, that the terror is not conclusive, and that if the experience can expand fully, a positive experience is likely to emerge. This is the reasoning behind Rommer's reassurance: "I explained to [her] that I believe with all my heart that had she not been resuscitated as rapidly as she was, ... a wonderful peaceful experience would have unfolded" (2000, p. 53). Bache, basing his statement on clients who have worked through the stages of Grof's perinatal matrices, has emphatically asserted that "A frightening NDE is ... an incomplete NDE" (1994, p. 42). Although the overall evidence is not conclusive, reassurance sometimes has more value than data analysis.

Third, holy figures in all traditions have endured similar experiences-not only Saint Teresa (see above) and other saints, but shamans, Krishna, and perhaps Jesus. The experience certainly did not keep them from being holy, so something must be going on other than damnation or being lost.

Fourth, the Void is traditionally considered the ultimate experience in spiritual practice; people may work for years to achieve it. An unprepared person terrified by encountering the Void is like a first-time skier who has been forced onto the championship jumps at Olympic Village.

Fifth, for friends and therapists to keep in mind: The conceptions of "self" and "reality" in Western and Eastern faith traditions are very different. A struggling Western experiencer may become even more traumatized by the argument, based on Eastern thought, that the physical 
world and ego are merely illusions. Unless the person is already comfortable with those principles, arguments based on ego death are likely to create more anxiety than enlightenment.

Sixth, defuse the emotional intensity by, literally, getting it out. Lukeman (2000) suggested telling the story out loud three times; if there is no listener, saying it out loud anyway will help defuse the anxiety. From my own experience, this is highly effective. Some people may feel less threatened by writing the experience first, then reading the text out loud.

\section{Later Exploration}

The suggestions in this section assume that although a person may be troubled and fearful, there is no pathology. In the case of emotional fragility, psychotherapeutic help should be sought before anything else.

At some undefinable time, if the experience has not been too deeply repressed, one will probably want to begin exploring ways of thinking about it. There is no timetable and no prescribed route. These are a few of many possible paths; they are here because they have been helpful in resolving my own experience. It should be noted that where suggested approaches are religious in nature, they expand considerably beyond literal interpretations.

Questions will likely be directed, very possibly with anger, toward God and religion. This is not the time for experiencer or helper to think (or say), "Oh, you mustn't think that." Nor is it the time for Jonathan Edwards' "Sinners in the Hands of an Angry God." There are healing and whole-making approaches: Harold Kushner's When Bad Things Happen to Good People (1994) and Edinger's commentary on Job, Encounter with the Self (1986), both of which I highly recommend; any Alan Watts; Marcus Borg; the literature of the Hasidic Baal Shem Tov and his followers; Matthew Fox's Original Blessing (1983); Lawrence Kushner's Honey from the Rock (1977) or God Was in This Place and I, I Did not Know (1991); and Isaiah, the Psalms, and John rather than Jeremiah or Revelation (which can come much later).

Work from the premise that a terrifying NDE is a different kind of spiritual experience; this means there is value in it, not a categorical casting-out or sign of dysfunction. The focus then shifts from "Why did this happen to me?" to "What meaning can I find in this?"

If there is an eleventh Commandment, it must be, "Thou shalt do thy inner work." It is not possible to dance the spiritual dance while the floor is littered with psychodynamic rubble. To experiencers, my 
strongest recommendation is: Begin to clear the floor. Find a therapist to help you identify your personal issues; if you can't afford long-term help, pick one issue and work with a therapist short-term; if you can't afford that, apply to a clinic; and if you still can't afford that, get a library card and begin reading. This is not a short-term project and it is not the only task, but it is absolutely essential.

As soon as possible - which may be quite a long time later-it may be productive to name the issues that made the experience so frightening: Was it being out of control; or unfamiliarity, or oddness; the threats of perceived entities? What about that issue makes it feel like such a threat? Some short-term cognitive therapy may be useful, especially with issues related to control.

Discover the techniques developed for dreamwork and imaging. This information is invaluable. As Wayne Rollins observed, NDEs read like dream material; decoding symbols applies to deciphering NDEs and similar experiences as well as dreams. This does not mean simply pairing images from an experience with those listed in a booklet on dreams found at the supermarket. A simple and excellent introductory book is psychotherapist Alex Lukeman's Nightmares (2000); a near-death experiencer himself, Lukeman approaches dreamwork with respect, thorough training, and groundedness. Other reputable authors on dreamwork include John Sanford, Morton Kelsey, and Louis Savary. A grounded course or workshop, or working for a while with a Jungian therapist, skilled at dreamwork, may help.

Lukeman listed seven keys for finding relief from the fear of nightmares. Equally applicable to NDEs and similar experiences, the keys are:

Realize the [experience] didn't occur just to scare you, but has meaning and purpose. This is absolutely fundamental....

You have an innate ability to understand and gain relief from the [experience].

Don't be afraid to look at horrifying images, or think that bad images mean bad things about you.

Learn to step away and consider the image objectively, without emotion, if possible.

If you get an idea of the meaning, you get two good results: You won't have to have the dream again and you have practical advice for your real, outer life.

Remind yourself that nightmares can open the door to love and healing in both a psychological and a physical sense. They are a gift from your unconscious mind, even though they seem frightening when they occur.

Let your mind relax; freely associate images, feelings, and memories. (2000, p. 10) 
Other basic dreamwork techniques for the experiencer include the following:

Amplify the experience; give it a title; name the theme. What can you say about the theme?-free-associate a bit. Where else (in movies, literature, scripture) does that theme appear? What parallels are there between those stories and the NDE? Then sit with them for a while; how could you understand the theme and the parallels to apply to issues in your life? Do the same thing with the elements (the places, the characters) of the experience.

Think of hero's journeys in legend and video games: The hero carries a talisman and goes with a companion. Approach your NDE mentally, carrying in your mind (or, for that matter, in your hand) a talisman to protect you, and with a companion-living or not, whom you actually know or not-to help you through the experience. Notice what and whom you chose and what significance they have for you; free-associate and amplify what you can say about them, as above. See if events in your experience shift, and how.

What could you have done differently during the actual experience? Now that you can participate consciously in the events, you are able to change your responses, to observe relationships, to try "going with" the experience. What differences do new approaches make?

There are a number of others approaches that may be helpful:

Expand the Symbols: What Else Could They Mean? Fire, for instance, which we generally interpret as the worst sort of punishment, has an honorable history as a symbol of cleansing, purification, and rebirth (for example, the Phoenix rising). Darkness, weeping, gnashing of teeth may be not indications of a quasi-physical Hell but, as theologian Hans Kung pointed out, "harsh-sounding metaphors for the menacing possibility that a person may completely miss the meaning of his life" (1984, P. 140). As in dreams, a suggestion of death may point not only to the end of physical existence but to the end of a life phase or a major change in one's awareness. The Void may feel like ultimate abandonment; it can also represent ultimate unity to someone who is ready to experience it that way. A horned creature, instantly terrifying as Satan, has an ancient history as a guide. The more one knows about symbolic language, the wider the possible range of interpretations.

Use Both Sides of Your Brain: First, Get Into Your Head. This cannot be over-stressed: Find the best information you can from as many sources as you can. Find views you agree with and views you don't. Build an educated understanding of the subject. Read, read, read, especially 
outside the near-death literature. Read transpersonal psychology, the history of science, the perennial philosophy, a modern translation of the Bible, the Koran and Baghavad Gita; the "new physics," consciousness studies, metaphysics, contemporary theology, general books about religions other than your own; read hymn lyrics and poetry; read the mystics and Joseph Campbell; read dreamwork and imaging techniques, and about healing. If you are a spiritual person, read science; if you love science, read the mystics. (Sometimes the least comfortable ideas may trigger something and become the most useful in the long run.) Do not read only near-death, only New Age, only evangelical-only anythingliterature.

Listen to tapes of conferences and lectures. Listen with a critical ear, not to find fault with the presenter but to hear patterns, themes, and inconsistencies. Beware of people who insist they have the definitive answer. Go to conferences; take courses. If you cannot afford them, find inexpensive books and tapes at the public library; attend discussions at a compatible church or temple (if secular, try Unity, Bahá'í, or a Unitarian/Universalist church or your faith's equivalent); find a pertinent short-term adult education course at the nearest high school or community college. Always, always, be cautious of people who are absolutely certain their opinions are absolute Truth. Through it all, recognize that you are vulnerable to charlatans, bad information, and being ripped off. You will want a guru; be careful choosing your role models. Take your time. Do not commit to any person or group that will not easily let you go. Remember that spiritual growth cannot be bought; higher price does not inevitably mean higher consciousness.

Next, get out of your head. Paint your experience; sculpt it; weave it; dance it. If you can't dance, walk it; if you are physically paralyzed, imagine how it would feel to dance it. If you do crafts, make something of it. We are most accessible to sudden insight from our weakest aspect: So, if you ordinarily function from strong verbal skills, try something kinesthetic. If you prefer physical activity, read poetry or keep a journal.

Find Interpretations of the Experience That Differ From Yours. Every interpretation represents a different model of the experience-but they are all models, not the real thing. Look at different models-the concretist (literal) model, a variety of "explain it away" reductionist models (that nevertheless contain useful information), the Jungian ego-Self model, a holographic universe model, an apocalyptic model, ecumenical religious, conservative religious, scientific, metaphysical, and on and on. 
Notice how these models are alike, how different. Discover which ones feel most comfortable and uncomfortable, and then examine why-not "Why is my interpretation right and that one wrong," but what do your choices say about what is important to you?

Identify the Vocabulary That Registers With You. Different models have different vocabularies. Find your vocabulary; for example, some people find that working with psychological terminology opens doors, while others consider it just psychobabble. Then remember that the words build a model, not the real thing. No one has the single definitive vocabulary or interpretation.

Find the Story That Speaks to You. Maybe Job; or Jacob wrestling all night by a river until he is wounded by an unidentified being; or the Aeneid or another hero's journey. Maybe Frodo, the peaceable hobbit, venturing into a realm of evil for the sake of his community. Read or see the film versions of J. R. R. Tolkien's Lord of the Rings (1954-55) and C. S. Lewis' Chronicles of Narnia (1950-1956). Explore reviews or other interpretations of the story that can help deepen your understanding.

What is the Gift Within the Experience? This is a question that may take years to answer. It is the mythic version of "All things work together for good to them that love God" (Romans 8:28), or Jacob's insistence after wrestling all night with a mysterious unnamed entity that, "I will not let thee go, unless thou bless me" (Genesis 32:26). Insist on finding the gift, the blessing of your experience, how it provides an avenue for your maturity and wholeness.

Recognize What Can be Expected From a Resource. A clinical psychologist may be skilled at helping unravel life-history material but not dream symbols. A spiritual director works with a person's relationship to the Sacred, not with deep-seated psychological problems. At any given point, one may be more helpful than another.

Identify a Community. The work is always done alone, but others will help. Caution and discernment are crucial; this is harder than a finding a dentist. Some IANDS support groups are able to be helpful; others are too fearful, or too enamored of the radiant experience to tolerate the depths. For the person who has given up religion, it is worth the attempt to go back to services: to the tradition of childhood, if there was one, or, if that is uncomfortable, looking ("shopping around" is fine for this) for one that better meets the needs of today. In some geographic areas, it may be possible to find a spirituality group or book club with which to 
discuss related issues. Be careful; these can be wonderful but are often the targets of especially needy and/or ungrounded folks who will drain emotional energy and talk nonsense rather than encourage genuine understanding and growth. Like some support groups, they may offer few resources for dealing with the shadow side of spirituality. This same caution applies to some Bible study groups; if they are unable to tolerate the idea of fearfulness - or conversely, if they demonstrate unbalanced interests in punishment and predictions of satanic influence more than in living affirmatively with the Holy-find another group.

\section{Conclusions}

I have been talking about the work of a lifetime. The twin temptations of light and dark near-death and similar experiences are: paralysis. With transcendent experiences, the temptation is, oddly enough, to a paralysis of self-satisfaction, of believing the questions have all been answered, the work done. With horrifying experiences, the temptation is to the paralysis of despair, not going on, giving up. But when one presses on, the objective is the same: to arrive at the place of Erikson's ego integrity, when we know-at last-our place, and our time, and who we really are. In Edinger's words:

There is in the unconscious a transpersonal center of latent consciousness and obscure intentionality. The discovery of this center, which Jung called the Self, is like the discovery of extraterrestrial intelligence. Man is now no longer alone in the psyche and in the cosmos. The vicissitudes of life take on new and enlarged meaning. Dreams, fantasies, illness, accident and coincidence become potential messages from the unseen Partner with whom we share our life.

At first, the encounter with the Self is indeed a defeat for the ego; but with perseverance, Deo volente, light is born from the darkness. One meets the "Immortal One" who wounds and heals, who casts down and raises up, who makes small and makes large-in a word, the One who makes one whole. $(1972$, p. 9)

It is that wholeness we are after.

No one would wish on the firefighters or police of New York City the task of clearing the ghastly wreckage of the Twin Towers. No one would hope, ever, for ironworkers to endure a struggle like that of tediously, day after day, picking their way through such carnage. Yet it is those labors, and the persistence and integrity of the crews, that has made them the heroes of the modern archetypal descent to an underworld beyond imagining. 
They are the wounded healers. No one would wish for the experience; yet, once it arrives, one wishes to meet it with knowledge, and courage, and compassion, recognizing that eventually the city will be remade. The gift to the workers may be being part of such an archetypal restoration, or growth to a larger wholeness, the workers and the nation marked to perpetuity by a new depth and a knowledge of suffering.

These are not the gifts one asks for, but in the incomprehensible fullness of human experience, they are sometimes those one is required to find.

One can draw similar conclusions about frightening near-death experiences. They are neither trivial nor meaningless. As radiant experiences represent the heights of numinous encounter, those that are terrifying represent the depths; neither type reflects only the degree of perfection or brokenness of the experiencer.

Certainly it is possible, as with any unfathomable phenomenon, to concretize the experience and attempt, by ritual or law or words, to disempower it. Certainly it is possible to discount or deny the unwelcome event, to claim it is something other, to disavow its significance. But those are avoidance techniques, as they are in any effort to escape an unwanted reality.

If there is a single conclusion to be drawn here, it may be that we are called to a higher level of understanding: to recast our assumption that pain is equivalent to punishment, that suffering is in itself malevolent, that there is no gift in the dark. Identification with an appropriate archetype and expansion of the meaning of their own symbols can help people move toward resolution of these experiences with a profound sense of the Mystery we share with all of human history.

\section{References}

Atwater, P. M. H. (1992) Is there a hell? Surprising observations about the near-death experience. Journal of Near-Death Studies, 10, 149-60.

Bache, C. M. (1994). A perinatal interpretation of frightening near-death experiences: A dialogue with Kenneth Ring. Journal of Near-Death Studies, 13, 25-45.

Budge, E. A. W. (Ed.). (1967). The book of the dead: The papyrus of Ani. New York, NY: Dover. (Original work written 13 th century B.C.)

Clark, K. (1984). Clinical interventions with near-death experiencers. In B. Greyson and C. P. Flynn (eds.), The near-death experience: Problems, prospects, perspectives (pp. 242255). Springfield, IL: Charles C. Thomas.

Corbett, L. (1996). The religious function of the psyche. London, England: Routledge.

Edinger, E. F. (1972). Ego and archetype. New York, NY: Putnam.

Edinger, E. F. (1986). Encounter with the self: A Jungian commentary on William Blake's Illustrations of the book of Job. Toronto, Canada: Inner City Books. 
Eichmann, W. C. (1991). In C. Zweig and J. Abrams, Meeting the shadow: The hidden power of the dark side of human nature. Los Angeles, CA: Tarcher/Perigee.

Ellwood, G. F. (2001). The uttermost deep: The challenge of near-death experiences. New York, NY: Lantern Books.

Evans-Wentz, W. Y. (Ed.). (1957). The Tibetan book of the dead. London, England: Oxford University Press. (Original work written 11th century.)

Flynn, C. P. (1985). After the beyond: Human transformation and the near-death experience. Englewood Cliffs, NJ: Prentice Hall.

Fox, M. (1983). Original Blessing: A primer on creation spirituality. Los Angeles, CA: Tarcher/Putnam.

Gallup, G., and Proctor, W. (1982). Adventures in immortality: A look beyond the threshold of death. New York, NY: McGraw Hill.

Grey, M. (1985). Return from death: An exploration of the near-death experience. London, England: Arkana.

Greyson, B., and Bush, N. E. (1992) Distressing near-death experiences. Psychiatry, 55, 95-110.

Grof, S. (1975). Realms of the human unconscious. New York, NY: Dutton.

Grof, S. (1994, Winter). Alternative cosmologies and altered states. Noetic Sciences Review, No. 32, pp. 21-29.

Grof, S., and Grof, C. (1980). Beyond death: The gates of consciousness. New York, NY: Thames and Hudson.

Grosso, M. (1983). Jung, parapsychology, and the near-death experience: Toward a transpersonal paradigm. Anabiosis: The Journal of Near-Death Studies, 1, 326.

Hoffman, R. (1995a). Disclosure needs and motives after a near-death experience. Journal of Near-Death Studies, 13, 237-266.

Hoffman, R. (1995b). Disclosure habits after near-death experiences: Influences, obstacles, and listener selection. Journal of Near-Death Studies, 14, $29-48$.

Ingall, M. (2000, July). Stairway to Heaven? Mademoiselle, pp. 94-96.

Kung, H. (1984). Eternal Life: Life after death as a medical, philosophical, and theological problem. Garden City, NY: Doubleday.

Kushner, H. (1994). When bad things happen to good people. New York, NY: Avon.

Kushner, L. (1977). Honey from the rock: An introduction to Jewish mysticism. New York, NY: Jewish Lights.

Kushner, L. (1991). God was in this place and I, I did not know: Finding self, spirituality and ultimate meaning. Woodstock, VT: Jewish Lights.

Lewis, C. S. (1950-56). The chronicles of Narnia. New York, NY: Collier.

Lukeman, A. (2000). Nightmares: How to make sense of your darkest dreams. New York, NY: M. Evans.

Marty, M. E., and Appleby, R. S. (1992). The glory and the power: The fundamentalist challenge to the modern world. Boston, MA: Beacon Press.

Otto, R. (1958). The idea of the holy. London, England: Oxford University Press.

Rainer, R. (Ed.). (1957). Ars moriendi: Von der Kunst des heilsames Lebens und Sterbens. Koeln-Graz, Germany: Boehlau Verlag. (Original work written 15th century.)

Rawlings, M. (1978). Beyond death's door. Nashville, TN: Thomas Nelson.

Rawlings, M. (1980). Before death comes. Nashville, TN: Thomas Nelson.

Rawlings, M. (1993). To hell and back. Nashville, TN: Thomas Nelson.

Ring, K. (1994). Solving the riddle of frightening near-death experiences: Some testable hypotheses and a perspective based on A course in miracles. Journal of Near-Death Studies, 13, 5-23.

Rommer, B. (2000). Blessings in disguise: Another side of the near-death experience. St. Paul, MN: Llewellyn.

Sanford, J. A. (1970) The kingdom within. New York, NY: Paulist Press.

Spong, J. S. (1992). Rescuing the Bible from fundamentalism. San Francisco, CA: Harper. 
Storm, H. (2000). My descent into death: And the message of love that brought me back. London, England: Clairview Books.

Tolkien, J. R. R. (1954-55). The lord of the rings. London, England: Allan and Unwin.

Wink, W. (1986). Unmasking the powers: The invisible forces that determine human existence. Philadelphia, PA: Fortress Press.

Virgil. (1909). Aenied (trans. By J. Dryden). New York, NY: Collier. (Original work written 19 B.C.)

Zaleski, C. (1987). Otherworld journeys: Accounts of near-death experience in medieval and modern times. New York, NY: Oxford University Press.

Zweig, C., and Abrams, J.(1991). Meeting the shadow: The hidden power of the dark side of human nature. Los Angeles, CA: Tarcher/Perigee. 